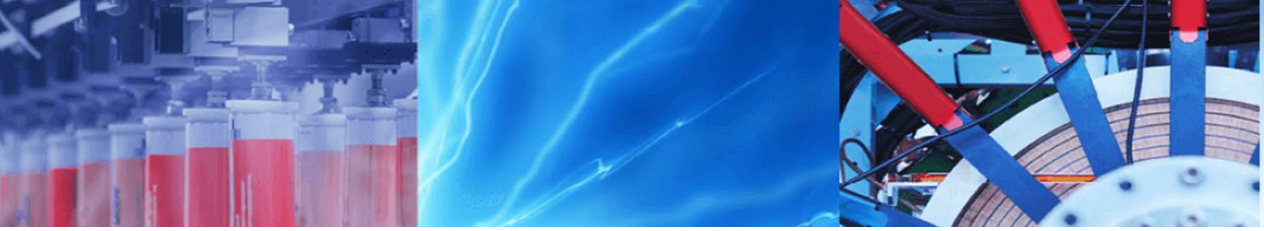

Research Article

\title{
Effect of reinforcements and processing method on mechanical properties of glass and basalt epoxy composites
}

\author{
C. R. Raajeshkrishna ${ }^{1}$ (I) P. Chandramohan ${ }^{2}$
}

Received: 19 January 2020 / Accepted: 15 April 2020 / Published online: 25 April 2020

(c) Springer Nature Switzerland AG 2020

\begin{abstract}
The effect of reinforcement material and manufacturing method on tensile, impact, and hardness properties of glass and basalt laminated composites were studied. Woven glass and basalt fabrics were used as reinforcements along with a thermosetting epoxy matrix to fabricate the laminate composites. The glass and basalt epoxy composites were made using hand layup with compression, vacuum bagging, and vacuum-assisted resin infusion methods. The characterization tests are performed as per the ASTM D638-10, ASTM D256, and ASTM D2240 standard respectively. The basalt epoxy composites show improved mechanical properties compared to the glass-epoxy composites. Further, hand layup, along with compression moulding and resin infusion methods, were found to be beneficial in improving the mechanical properties of the composites. Field emission scanning electron microscopic analysis conveyed the adhesion between fibers and resin as well as the voids retained within the matrix are the dominant factors that determined the mechanical properties of the laminated composites such as tensile, impact strength and hardness.
\end{abstract}

Keywords Basalt · Glass · Processing methods · Voids · Mechanical properties

\section{Introduction}

Due to high stiffness to weight ratio and high process ability, the fiber-reinforced polymer composites are used in aerospace, automobile, marine and defense sector [1]. The reinforcement of fibers escalates the properties of the composite materials [2]. Design methodologies also have been proposed to reduce the aircraft weight by using more than $50 \%$ of primary structural components by fiber reinforced epoxy composites [3]. The reinforcing phase can be in the form of fibers (short and long), particles, or flakes. The critical length that decides the short/long fiber is $10 \mathrm{~mm}$. The commonly used composites in aircraft industry include polymer matrix composites (PMC) and metal matrix composites (MMC). Few studies also been reported in improving the properties of the polymer composites by using alternative manufacturing method to achieve high performance composites. According to the form of reinforcing material and matrix, the manufacturing method varies $[2,4]$. In the domain of the polymer matrix with fiber reinforcement, there are different manufacturing methods suggested by the diverse research group for aeronautical/ marine applications [1-4].

Kanthraju et al. [1] fabricated glass-basalt hybrid fiber with and without fillers like graphite and Polytetrafluoroethylene (PTFE) using hand layup followed by compression moulding. The experimental investigations on the loading of graphite filler to glass basalt hybrid fiber reinforced composites shows superior mechanical performance compared to unfilled and PTFE filled composites [1]. Mechanical behaviour, microstructure and crack propagation of glass, basalt and carbon fabric reinforced

C. R. Raajeshkrishna, rajesh17171@gmail.com; P. Chandramohan, pcmohu@yahoo.co.in | ${ }^{1}$ Department of Aeronautical Engineering, Nehru Institute of Engineering and Technology, Nehru Gardens, T.M Palayam, Coimbatore, Tamilnadu 641105, India. ${ }^{2}$ Department of Mechanical Engineering, Sri Ramakrishna Engineering College, Coimbatore, Tamilnadu 641022, India. 
mono and hybrid epoxy composites prepared by hand layup method for wind turbines have been investigated by Tamas et al. [6]. The result shows the similar behaviour of glass and basalt reinforced composites by the similar crack propagation method [6]. Residual strength and damage characterization of glass fiber, basalt fiber and its hybrid reinforced in epoxy laminates prepared using hand layup method were studied by Andrew et al. [7]. The result from compression after impact test shows that glass laminate possessed the highest resistance to impact damage. The low-velocity impact behaviour of hybrid composite laminates prepared by hand layup was investigated by Behnia et al. [8]. The alternative layers of the aramid, glass, basalt, and carbon fabrics (hybridization) reinforced in epoxy improves the mechanical performance of composites [8]. Colombo et al. [9] identified basalt fibers as a valid alternative to carbon and glass fibers for their lower cost and strength respectively. Subagia et al. [10] investigated the performance of the carbon-basalt/epoxy hybrid composites prepared using vacuum-assisted resin transfer moulding (VARTM) by subjecting it to flexural load. The results showed that the flexural properties strongly depended on the reinforcing position of carbon and basalt fabric [10]. Bozkurt et al. [11] experimentally investigated the effect of basalt fiber hybridization on vibration damping and tensile properties of carbon fiber/epoxy composites prepared using VARTM process. The results showed that incorporation of basalt fiber into the carbon fiber/epoxy composites significantly affected the tensile strength, tensile modulus and enhanced damping properties [11]. Fiore et al. [12] evaluated the influence of external layers of basalt on the durability behaviour of flax reinforced epoxy composites prepared using vacuum bagging method (VBM). The experimental results convey that the hybridization with basalt fibers can be considered as a practical approach for enhancing the durability of natural fibers composites under salt-fog environment conditions [12]. In another work, Fiore et al. [13] evaluated the influence of uniaxial basalt fabric layers on the mechanical performances of a glass mat/epoxy composite prepared using VBM for marine applications. Presence of two external layers of basalt has been identified as the contributing factor for the highest increase in mechanical properties of hybrid laminates compared to those of GFRP laminates [13]. Lopresto et al. [14] conducted experiments on E-glass and basalt fiber by reinforcing in the plastic matrix using VBM to replace glass fibers in most of the applications. The results show the high performance of the basalt material in terms of young modulus, compressive and bending strength, impact force and energy [14].

From the literature, it is clear that different views have been shown by various researchers. Therefore, focused research on the effect of reinforcement material (glass and basalt fabric) and manufacturing method (HLC, VBM, VARIM) on mechanical properties is required to fabricate glass and basalt reinforced epoxy composite and this research work attempts on doing that.

\section{Experimental details}

E-glass fabric (220 GSM) and basalt fabric (230 GSM) were used as bi directional plain woven reinforcements in an epoxy polymer matrix. The matrix system used is an epoxy resin (LAPOX-L12) and a K-6 hardener (aromatic amines) supplied by Atul Limited, Gujarat, India. LAPOX$\mathrm{L} 12$ is a pale yellow liquid epoxy resin with medium viscosity. Hardener K-6 is a low-viscosity room temperature curing liquid. The resin hardener mixture is prepared by mixing resin and hardener in 10:1 ratio. The fabrics used for making hybrid composites were prepared by cutting the fabric to the required size $(298 \mathrm{~mm} \times 123 \mathrm{~mm})$ accurately by means of computer numerically controlled (CNC) board cutting machine. The accuracy maintained here is to attain the proper matrix reinforcement ratio. All the glass and basalt composites were prepared by maintaining glass fabrics ( 22 layers) and basalt fabrics (18 layers) for all the manufacturing method. The layers used in the current investigation is arrived from the previous investigation [15]. Three methods were used to fabricate the composites. The properties of reinforcements and matrix are shown in Table 1 and the details of the laminated composites under study are shown in Table 2.

\subsection{Hand layup along with compression moulding}

The composites were fabricated by placing a suitable number of accurately cut glass fabrics (22 layers) and basalt fabrics (18 layers). LAPOX L- 12 resin and K-6 hardener were used in the hand layup process. The epoxy hardener mixture is applied on the fabric surface followed by applying pressure through hand rollers. The hand layup process is followed with compression moulding in the die using compression moulding machine. The process parameters maintained in the compression moulding process were pressure of $10 \mathrm{bar}$ and a temperature of $100^{\circ} \mathrm{C}$. The die

Table 1 Physical and mechanical properties of reinforcement and matrix [15]

\begin{tabular}{llll}
\hline Properties & E-glass fiber & Basalt fiber & Epoxy resin \\
\hline Density, $\mathrm{kg} \mathrm{m}^{-3}$ & 2550 & 2750 & 1290 \\
Tensile modulus, GPa & $70-76$ & 89 & 2.73 \\
Tensile strength, MPa & 2500 & 3150 & 30 \\
Elongation at break, \% & $1.8-4.8$ & 3.15 & 2 \\
\hline
\end{tabular}


Table 2 Details of the laminated composites under study

\begin{tabular}{|c|c|c|c|}
\hline Specimen code & HLC & VBM & VARIM \\
\hline Manufacturing method & $\begin{array}{l}\text { Hand layup followed by compression } \\
\text { moulding }\end{array}$ & $\begin{array}{l}\text { Vacuum bag- } \\
\text { ging method }\end{array}$ & $\begin{array}{l}\text { Vacuum } \\
\text { assisted } \\
\text { resin } \\
\text { infusion } \\
\text { method }\end{array}$ \\
\hline Process parameter & $\begin{array}{l}\text { Hand pressure through rollers } \\
\text { Manual resin filling through brush }\end{array}$ & $\begin{array}{l}\text { Vacuum pres- } \\
\text { sure } \\
\text { Resin through } \\
\text { Vacuum } \\
\text { pump }\end{array}$ & $\begin{array}{l}\text { Vacuum } \\
\text { pressure } \\
\text { Vacuum } \\
\text { pump and } \\
\text { resin injec- } \\
\text { tion }\end{array}$ \\
\hline
\end{tabular}

was kept in closed position for $24 \mathrm{~h}$ to maintain the uniform compaction pressure. The pressure applied in the compression moulding helps to achieve the uniform thickness of the composites. The plate was taken out from the die and cured in the direct sunlight for another $24 \mathrm{~h}$. The thickness of the composites obtained under this method is in the range of $3 \mathrm{~mm}$.

\subsection{Vacuum bagging method}

The glass and basalt epoxy composites were made using the vacuum bagging method (VBM). This method involves an initial hand lay-up phase using glass fabrics (22 layers) and basalt fabrics (18 layers) and resin hardener mixture followed with polymerization of the mixture in a flexible bag in which negative pressure is reached by a vacuum pump. The air leakage is the challenge faced here which is overcome through the operator's skill and experience. The other limitations in this method are non-reusable vacuum bag, flow distribution medium, peel ply, sealing tape and resin tubing. The polymerized laminates were allowed to cure at room temperature for $24 \mathrm{~h}$. The post curing were performed at $60^{\circ} \mathrm{C}$ for $8 \mathrm{~h}$. The post-curing stimulates the hardening mechanism between thermosetting resin and hardener and achieves the better mechanical properties of the composites. The thickness of the composites obtained under this method is in the range of $4.5 \mathrm{~mm}$.

The disadvantages vacuum bagging is Chance of air leakage is high and strongly depends on worker's skill, experience. The resin injection pressure is limited between the environmental pressure (e.g., the atmospheric pressure) and the vacuum.

\subsection{Vacuum assisted resin infusion method}

The composites were fabricated using vacuum assisted resin infusion method (VARIM). A stack of glass ( $22 \mathrm{~L}$ ) and basalt fabrics (18 L) were laid onto the mould, which was then sealed with vacuum bag. The applied vacuum created a pressure difference which sucked the resin hardener mixture into the fabric lay-up via spiral tubing. During the infusion stage, vacuum pressure was maintained at $78 \pm 10 \mathrm{kPa}(630 \mathrm{~mm}$ of $\mathrm{Hg})$ using a vacuum pump, which is a low-cost system. The excess resin rejected is retained within the suction tubes, unable to arrive the resin absorbed by the fabrics. The resin weight used is indicated from the calculation. Laminates were cured at $100{ }^{\circ} \mathrm{C}$ for $8 \mathrm{~h}$. The thickness of the composites obtained under this method is in the range of $4.25 \mathrm{~mm}$.

The resulting composite plates prepared using all the above methods were sliced using water jet machining (WJM) as per ASTM standard for tensile, hardness and impact strength. The machined samples were post cured in an air oven at $40{ }^{\circ} \mathrm{C}$ for $30 \mathrm{~min}$ to remove the moisture entrapped during WJM process. The tensile test was performed using an Instron universal testing machine (UTM) with a crosshead speed of $5 \mathrm{~mm} / \mathrm{min}$, as per ASTM: D63810 test standard. The Charpy impact test was performed using the swinging pendulum-type impact tester. The ASTM D256 standard is used to conduct impact test. The hardness test was executed using Shore D hardness tester as per ASTM D2240 standard. All the tests were conducted with five samples taken from each manufacturing method and the average values were taken for discussion. The outcomes of the mechanical tests were justified with field emission scanning electron microscope (FESEM) examination and Energy-dispersive X-ray spectroscopy (EDS) analysis carried out using ZEISS FESEM.

\section{Results and discussion}

\subsection{Tensile strength}

The tensile strength of glass and basalt epoxy composites prepared using hand layup followed by compression moulding method (HLC), vacuum assisted resin infusion method (VARIM) and vacuum bagging method (VBM) are shown in Fig. 1. The glass and basalt epoxy composites prepared using HLC, VARIM and VBM methods records the 


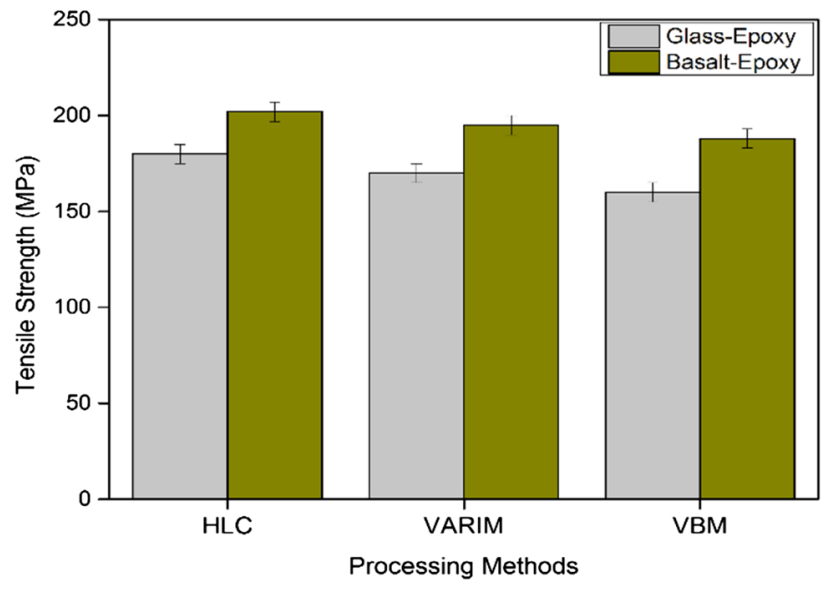

Fig. 1 The tensile strength of glass and basalt epoxy composites

tensile strength of $180 \mathrm{MPa}, 170 \mathrm{MPa}, 160 \mathrm{MPa}, 202 \mathrm{MPa}$, $195 \mathrm{MPa}$ and $188 \mathrm{MPa}$ respectively. It is evident that the tensile strength of basalt epoxy composites is higher than glass epoxy composites in all the manufacturing methods. The increase in tensile strength of basalt epoxy composites is due to the reinforcement of high tensile basalt fibers in the epoxy matrix [15].

Comparing the manufacturing methods, hand layup followed by compression moulding method achieves the highest tensile strength compared to other two manufacturing methods. The increase in the tensile strength is attributed towards removal of entrapped fine air bubbles in between the fabric layers and epoxy. The removal of entrapped air is achieved by combined effect of rollers used in the hand layup process and compaction pressure maintained during the compression moulding process as observed in the field emission scanning electron microscopic picture of Fig. 2. As a result of compaction, better interfacial adhesion is achieved between the fiber and the matrix which is also observed from the same figure. The EDS spectra of the basalt fiber reinforced in the epoxy matrix shown in Fig. 3 confirms the presence of $\mathrm{Si}, \mathrm{Al}, \mathrm{Ca}$, $\mathrm{Na}, \mathrm{Mg}, \mathrm{K}, \mathrm{Fe}$ and ferric oxides which constitute the composition of basalt $[16,17]$. In contrary to this result, Abdurohman et al. [5] have reported that vacuum assisted resin infusion method yields higher mechanical properties and the pump used to create the vacuum is responsible for the injection of resin into the fabrics.

\subsection{Impact strength}

The impact strength of glass and basalt epoxy composites under investigation is shown in Fig. 4. The glass and basalt epoxy composites records the impact strength of $80 \mathrm{~kJ} /$ $\mathrm{m}^{2}, 85 \mathrm{~kJ} / \mathrm{m}^{2}, 83 \mathrm{~kJ} / \mathrm{m}^{2}, 100 \mathrm{~kJ} / \mathrm{m}^{2}, 98 \mathrm{~kJ} / \mathrm{m}^{2}$ and $99 \mathrm{~kJ} / \mathrm{m}^{2}$ respectively. It is evident that the impact strength of basalt

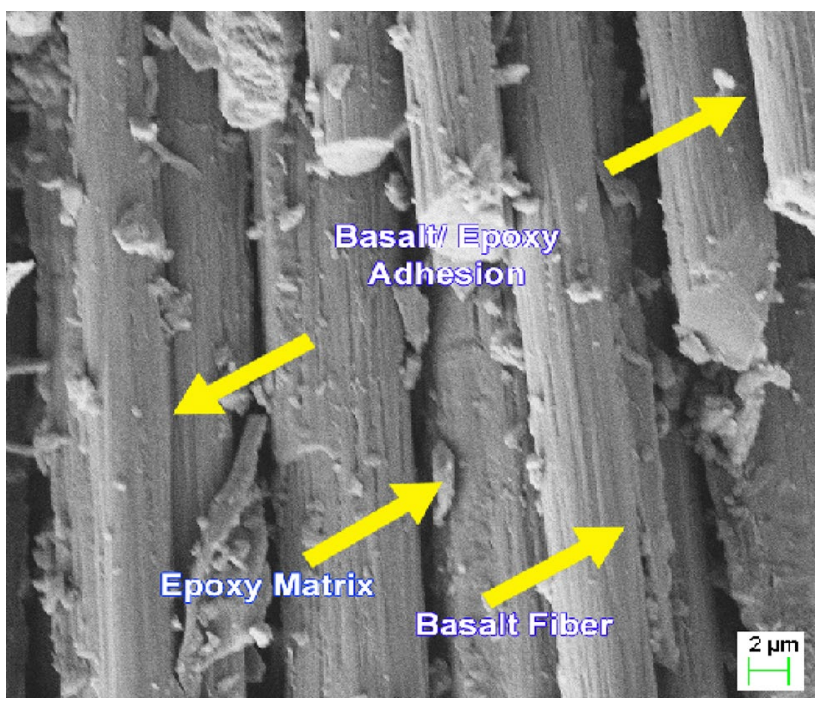

Fig. 2 The FESEM observation of basalt epoxy composite in HLC method

epoxy composites is higher than glass epoxy composites in all the manufacturing methods. The increase in impact strength of basalt epoxy composites is due to the chemical composition basalt fibers in the epoxy matrix [16]. Comparing the manufacturing method the HLC method achieves the highest impact strength compared to other two method. The increase in impact strength is attributed to the removal of entrapped air bubbles in between the fabric layers. The Figs. 5 and 6 depicts the FESEM observations of basalt epoxy composites prepared using HLC method and VARIM method respectively. Presence of voids/bubbles is not noticeable in the prior whereas the same can be witnessed in the later. The removal of

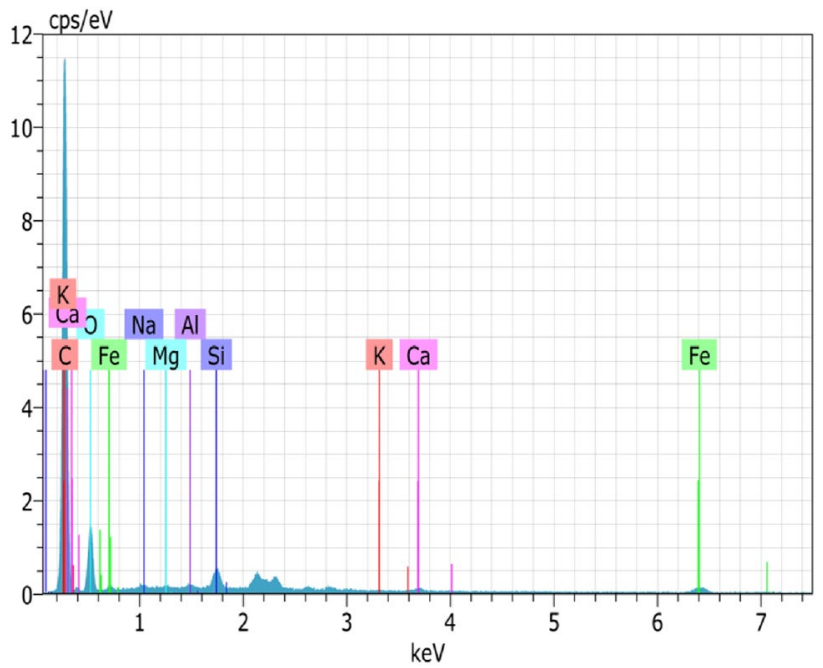

Fig. 3 EDS spectra of basalt fiber 


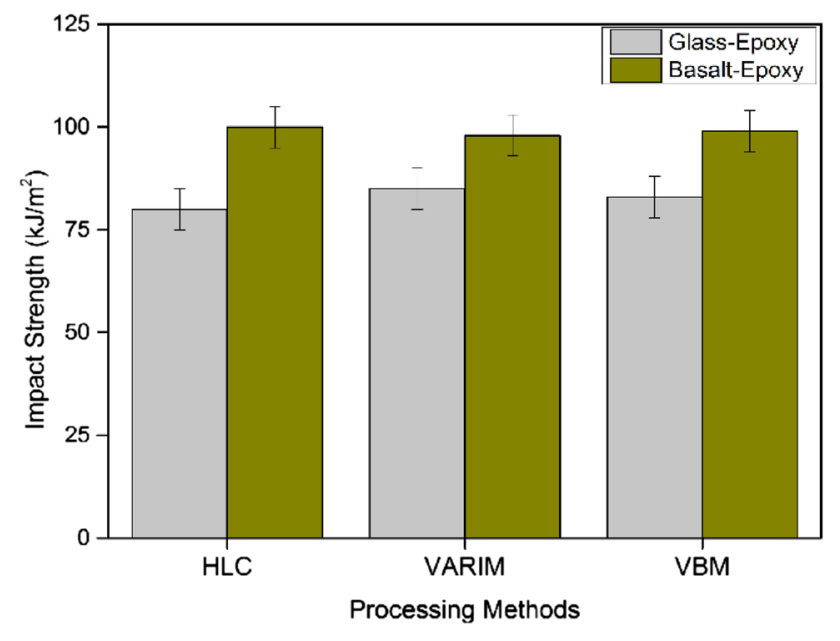

Fig. 4 The impact strength of glass and basalt epoxy composites

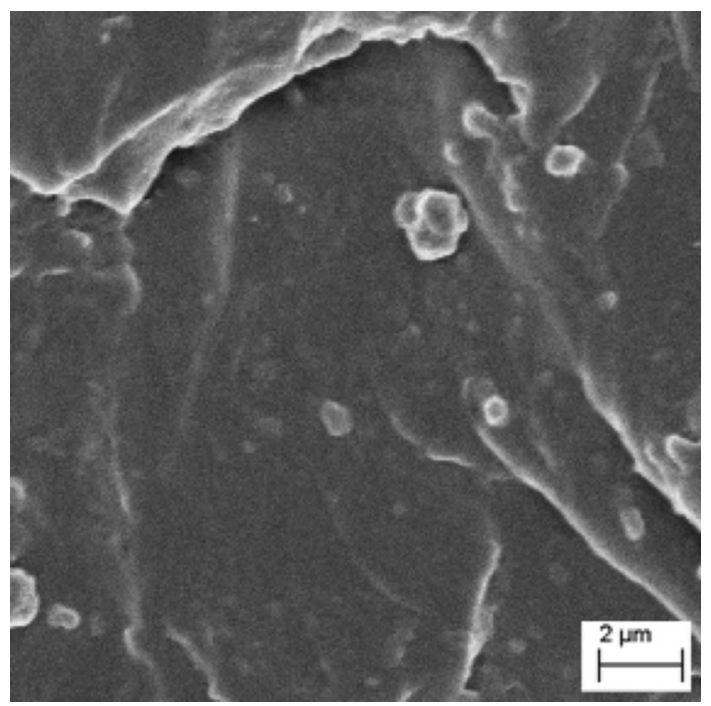

Fig. 5 FESEM observation of basalt epoxy composite using HLC method

entrapped air is achieved by combined effect of rollers used in the hand layup process and compression pressure.

\subsection{Hardness}

The shore D hardness of glass and basalt epoxy composites under investigation is shown in Fig. 7. The glass and basalt epoxy composites prepared using the above records the hardness of 78 SD, 75 SD, 73 SD, 99 SD, 95 SD and 90 SD respectively. It is evident that the hardness of basalt epoxy composites is higher than glass epoxy composites in all the manufacturing methods. The

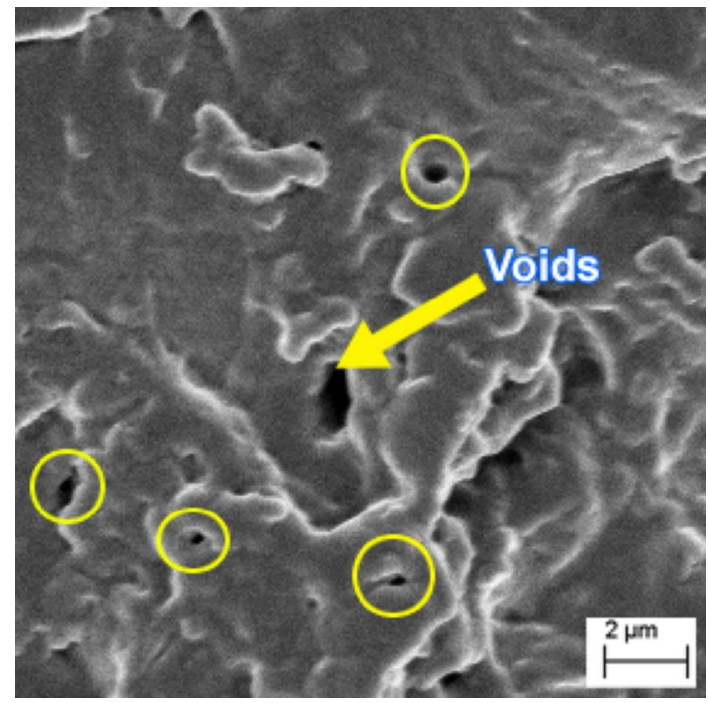

Fig. 6 FESEM observation of basalt epoxy composite using VARIM method

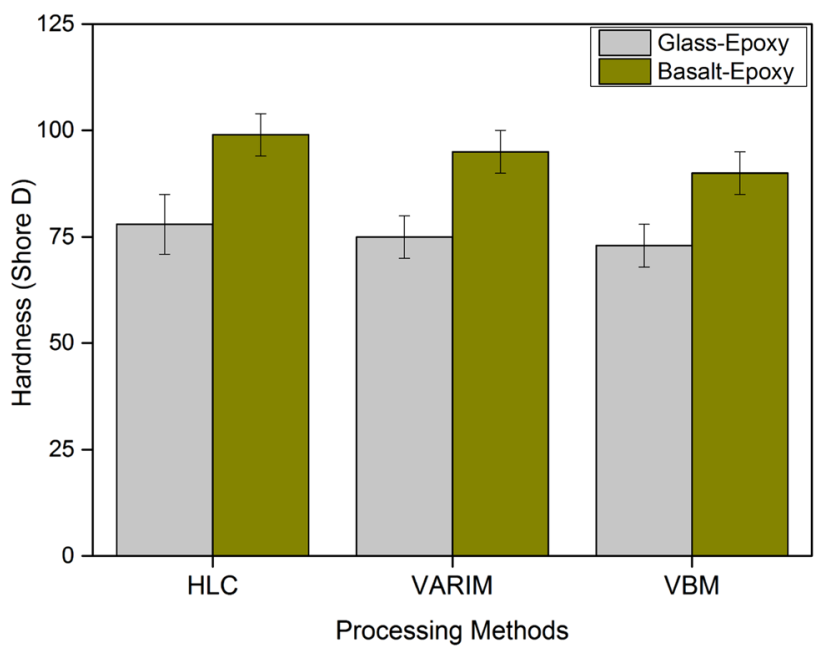

Fig. 7 Hardness of glass and basalt epoxy composites

increase in hardness of basalt epoxy composites is due to the reinforcement of harder basalt fibers in the epoxy matrix [15]. The hardness of the fiber is due to origin of basalt fibers from volcanic basalt rocks.

Comparing the manufacturing method the HLC method achieves the highest Shore D hardness compared to other two manufacturing methods. The increase in the hardness is attributed towards the adhesion achieved by basalt fibers in the epoxy matrix. The adhesion is achieved by the pressure applied through the rollers during the wetting of fabrics and the effective compaction pressure, an important factor which 
removes entrapped air bubbles thereby achieving the better mechanical properties of composites.

\section{Conclusion}

This investigation reports the result of mechanical characterization conducted on glass and basalt epoxy composites prepared using hand layup along with compression moulding, vacuum bagging and vacuum-assisted resin infusion method. The following conclusions were made.

1. Basalt epoxy composites is superior compared to glass-epoxy composites in the tensile performance.

2. The impact strength and hardness of basalt based composites are higher than that of glass epoxy composites.

3. Basalt epoxy composites exhibited superior mechanical properties when compared to glass-epoxy composites prepared using all the three methods.

4. Basalt fabric can be suggested as the best alternative material to the glass fabric in the epoxy matrix.

5. Hand layup followed with compression moulding method offers better mechanical properties compared to vacuum bagging and vacuum assisted resin infusion method.

\section{Compliance with ethical standards}

Conflict of interest The authors declare that they have no conflict interest.

\section{References}

1. Kanthraju BS, Suresha B, Saini MS (2015) Effect of type and filler loading on the static mechanical properties of glass-basalt hybrid fabric reinforced epoxy composites. Int J Adv Prod Mech Eng 1(5):60-70

2. Raajeshkrishna CR, Pradeep AS, Rishi Kumar RD (2019) Influence of fiber content on mechanical, tribological properties of short basalt fiber-reinforced nylon 6 and polypropylene composites.
J Thermoplast Compos Mater. https://doi.org/10.1177/08927 05719853613

3. Pora J (2003) Advanced materials and technologies for $A 380$ structure. Airbus Custom Serv 32:3-8

4. Saravanan D, Chandramohan P, Raajeshkrishna CR (2015) Evaluation of mechanical properties of B4C filled glass-epoxy composites. Int J ChemTech Res 8(4):1977-1981

5. Abdurohman K, Satrio T, Muzayadah NL et al (2018) A comparison process between hand lay-up, vacuum infusion and vacuum bagging method toward e-glass EW 185/lycal composites. J Phys Conf Ser 1130:1-11

6. Tamás P, Czigány T (2013) Investigation of mechanical properties and crack propagation behavior of hybrid composites with epoxy resin matrix. Mater Sci Forum 729:284-289

7. Andrew J, Ramesh C (2015) Residual strength and damage characterization of unidirectional glass-basalt hybrid/epoxy CAl laminates. Arab J Sci Eng 40:1695-1705

8. Behnia S, Daghigh V, Nikbin K et al (2016) Influence of stacking sequence and notch angle on the Charpy impact behavior of hybrid composites. Mech Compos Mater 52(4):489-496

9. Colombo C, Vergani L, Burman M (2012) Static and fatigue characterisation of new basalt fibre reinforced composites. Compos Struct 94:1165-1174

10. Subagia IDGA, Kim Y (2013) A study on flexural properties of carbon-basalt/epoxy hybrid composites. J Mech Sci Technol 27(4):987-992

11. Bozkurt OY, Gokdemir ME (2018) Effect of basalt fiber hybridization on the vibration-damping behavior of carbon fiber/epoxy composites. Polym Compos 39:E2274-E2282

12. Fiore V, Scalici T, Calabrese L et al (2016) Effect of external basalt layers on durability behaviour of flax reinforced composites. Compos B 84:258-265

13. Fiore V, Bella GD, Valenza A (2011) Glass-basalt/epoxy hybrid composites for marine applications. Mater Des 32:2091-2099

14. Lopresto V, Leone C, lorio ID (2011) Mechanical characterisation of basalt fibre reinforced plastic. Composites B 42:717-723

15. Raajeshkrishna CR, Chandramohan P, Saravanan D (2018) Effect of surface treatment and stacking sequence on mechanical properties of basalt/glass epoxy composites. Polym Polym Compos 27(4):201-214

16. Raajeshkrishna CR, Chandramohan P, Saravanan D et al (2018) Wear and friction behavior of basalt nanofillers reinforced epoxy nanocomposites. J Balk Tribol Assoc 244(3):484-495

17. Artemenko SE (2003) Polymer composite materials made from carbon, basalt, and glass fibres. Structure and properties. Fibre Chem 35:226-229

Publisher's Note Springer Nature remains neutral with regard to jurisdictional claims in published maps and institutional affiliations. 